Paper 306

\title{
Rolling Bearing Life Estimation based on Measured Wheel-Rail Forces for Conventional and Innovative Wheelsets
}

\author{
A. Bracciali and G. Megna \\ Dipartimento di Ingegneria Industriale \\ Università di Firenze \\ Italy
}

\begin{abstract}
Validation of bearings for railway wheelsets is performed by using international standards. This approach reflects both the long experience and the uncertainty in the actual loads that depends on the service performed by the vehicle. It is applicable only when "conventional" bearings are used, i.e. a pair of rolling bearings installed on journal seats at the end of the axle or between the wheels. This paper evaluates the life of such bearings on the basis of a given mixed service and compares it to the life of the bearings equipping a new wheelset with "apparently" independently rotating wheels.
\end{abstract}

Keywords: bearings, life estimation, independently rotating wheels, AIR wheelset.

\section{Introduction}

\subsection{Rolling bearings basics and railway standards}

Rolling bearings are the only type of bearings used nowadays in the railway industry for axleboxes. Their superior characteristics in terms of low friction and long life are such that journal (sliding) bearings disappeared many decades ago.

ISO 281 [1] is the international standard that defines the estimated bearings life according to the load, the dynamic load rating of the bearing and the type of rollers. The basic rating life is the "rating life associated with $90 \%$ reliability for bearings manufactured with commonly used high quality material, of good manufacturing quality, and operating under conventional operating conditions". It is defined as

$$
L_{10}=\left(\frac{C}{P}\right)^{p}
$$


where $P$ is the equivalent load, $C$ is the basic dynamic radial load rating, and $p$ depends on the type of rollers $(p=3$ for spheres, $p=10 / 3$ for cylindrical / tapered / toroidal rollers).

In the railway sector the European Standard EN 12082 [2] specifies the test programme that a wheelset bearing must pass to be qualified. This standard descends directly from the former UIC code 515-5 [3].

Conventional wheelsets are made of two wheels that are firmly connected to the axle. With this arrangement, the lateral force acting simultaneously on both the bearings that equip a wheelset is given by the algebraic sum $\Sigma Y$ of the lateral contact forces. This force is also the one that acts on the track and it is known as "track shifting force" or "ripage force". Track alignment is guaranteed if the track shifting force remains below the limit that was experimentally established by Prud'homme in 1967 [4]

$$
\Sigma Y \leq 0,85\left(10^{4}+\frac{F_{0}}{3}\right)
$$

where $F_{0}$ is the nominal vertical wheelset load based on the maximum mass $m_{\max }$ of the vehicle. This limit is still used in the latest standard EN 14363 [5] for running dynamics.

Vertical and lateral bearings testing loads are therefore respectively defined in EN 12082 [2] according to the following equations:

$$
F_{r n}=\frac{1,2}{2}\left(F_{0}-m_{0} g\right)=0,6\left(F_{0}-m_{0} g\right) \text { where } F_{0}=\frac{1}{j} m_{\max } g
$$

and

$$
F_{a n}=\frac{1,2}{2} * 0,5 * 0,85\left(10^{4}+\frac{F_{0}}{3}\right)=0,255\left(10^{4}+\frac{F_{0}}{3}\right)
$$

In these equations $m_{0} g$ is the weight of the wheelset and $j$ is the number of wheelsets of the vehicle. The coefficient 1.2 (i.e. an increase of $20 \%$ ) is applied to both vertical and lateral loads. About lateral forces, the $1 / 2$ and 0.5 factors applied to lateral load descend respectively:

- one from the fact that the two axleboxes react simultaneously under lateral forces, sharing the total track shifting force;

- the other one is "a factor to introduce an average lateral force throughout the operation".

It is evident that both the architecture of the wheelset and the "typical" service in terms of lateral forces are considered. This formulation proves to be effective for "conventional" arrangements.

\subsection{Calculation and limitations of the basic rating life}

Some interesting information about the practical calculation of the basic rating life can be found in the technical publication [6]. 
The $C / P$ values in (1) range from 6.6 for locomotives to 9.1 for multiple units, i.e. respectively $3 \div 5$ and 3 million km respectively. Radial and axial load are calculated as follows:

- the mean radial dynamic load $K_{r}$ in $\mathrm{kN}$ is calculated as $K_{r}=f_{0} f_{r d} f_{t r} G$, where $G=\left(G_{00}-G_{r}\right) / 2, f_{0}$ is the payload factor, $f_{r d}$ is the dynamic radial factor and $f_{t r}$ is the dynamic traction factor, $G_{00}$ is the maximum static axleload and $G_{r}$ is the weight of the wheelset;

- the mean axial bearing load $K_{a}$ in $\mathrm{kN}$ is calculated as $K_{a}=f_{0} f_{a d} G$, where $f_{a d}$ is the dynamic axial factor.

All the factors included in these calculations come from a hundred years of experience with rolling bearings in the railway wheelset sector. For example, the dynamic radial load factor $f_{r d}$ is used to take into account quasi static effects and range from 1.2 for freight wagons to 1.4 for locomotives, while the dynamic axial factor $f_{a d}$ ranges from 0.08 for multiple units (max speed $160 \mathrm{~km} / \mathrm{h}$ ) to 0.12 for locomotives.

It is important to stress again the fact that the lateral force, that changes almost continuously during service in winding lines, is considered through the use of an "equivalent" value which, as seen, is normally between $8 \%$ and $12 \%$ of the vertical load. From these loads it is possible to calculate the equivalent bearing load $\mathrm{P}$ in $\mathrm{kN}$ is as follows [6]:

- $P=F_{r}+Y F_{a}$ for tapered rolling bearings and spherical rolling bearings;

- $P=F_{r}$ for cylindrical rolling bearings

where $Y$ is the axial load bearing factor.

It is interesting to observe that the general equation of ISO 281 [1] that defines the equivalent load $P=X F_{r}+Y F_{a}$ is not used for tapered wheelset bearings. It is in fact applicable when $F_{a} / F_{r}>e=1.5 \tan \alpha$. As long as lateral forces are limited, railway tapered rolling bearings are built with a roller angle of $\alpha=10^{\circ}, e=1.5$ tan $10^{\circ}=0.264$, i.e. $F_{a}>0.264 F_{r}$. This condition never happens in this application where the equivalent continuous axial load is in the order of $0.08 \div 0.12 F_{r}$. The simplified equation $P=F_{r}+Y F_{a}$ can therefore be used.

This assumption is not valid neither in general nor in the case of the innovative wheelset described hereinafter, so the full equation $P=X F_{r}+Y F_{a}$ must be used. For face-to-face or back-to-back matched bearings arrangements $X=0.67$, and the following equations have been used [17]:

- $F_{a} / F_{r} \leq e \rightarrow P=F_{r}+Y_{l} F_{a}$

- $F_{a} / F_{r}>e \rightarrow P=0.67 F_{r}+Y_{2} F_{a}$

where values for $Y_{1}$ and $Y_{2}$ are known for each matched rolling bearings pair

The basic rating calculation method can be improved taking into account factors like lubrication, degree of contamination, misalignment, proper installation and environmental conditions that result in a service life that may deviate significantly from the calculated basic rating [6].

In this work only the basic rating is calculated, as all the other conditions will be considered invariant in all the simulated architectures. Although it is known that this 
result is poorly representative of the real life in actual service, it is used as a basis to compare the behaviour of the bearings equipping a novel wheelset concept with "apparently" independently rotating (AIR) wheels.

\section{The AIR Wheelset}

Recently one of the authors has proposed a wheelset arrangement in which wheels equipped with rolling bearings are mounted on stub axles, similarly to conventional IRWs, but are instead connected by a torsionally stiff shaft and a torque limiter ([7] $\div$ [12]) (Figure 1). The presence of the connecting shaft removes the most important drawback of conventional IRW arrangements, consisting in the permanent misalignment of the wheelsets during running, that implies a continuous flange contact and results in an unacceptable wear. This explains why no IRW are used in conventional railways but only in low floor - low speed tram vehicles.

The AIR wheelset is intended to reduce maintenance as the wheel can be disassembled, overhauled or replaced with a procedure that is very similar to the one used for lorries, i.e. the bogie frame only needs to be lifted and some screws removed to extract the wheel including the bearings and the brake discs. All serviceable parts are therefore accessible together [13].

The conventional wheelset can be considered as a simply supported rotating beam, where radial loads obviously generate radial loads on the bearings and lateral loads at the wheel/rail contact are converted in axial and radial loads on the bearings. As a result, no moments are acting on the axleboxes. The situation is much different for the bearings of the AIR wheelset, that are subjected to the entire lateral force acting at the wheel-rail contact as the beneficial effect of the axle that "short circuits" the lateral forces is not present.
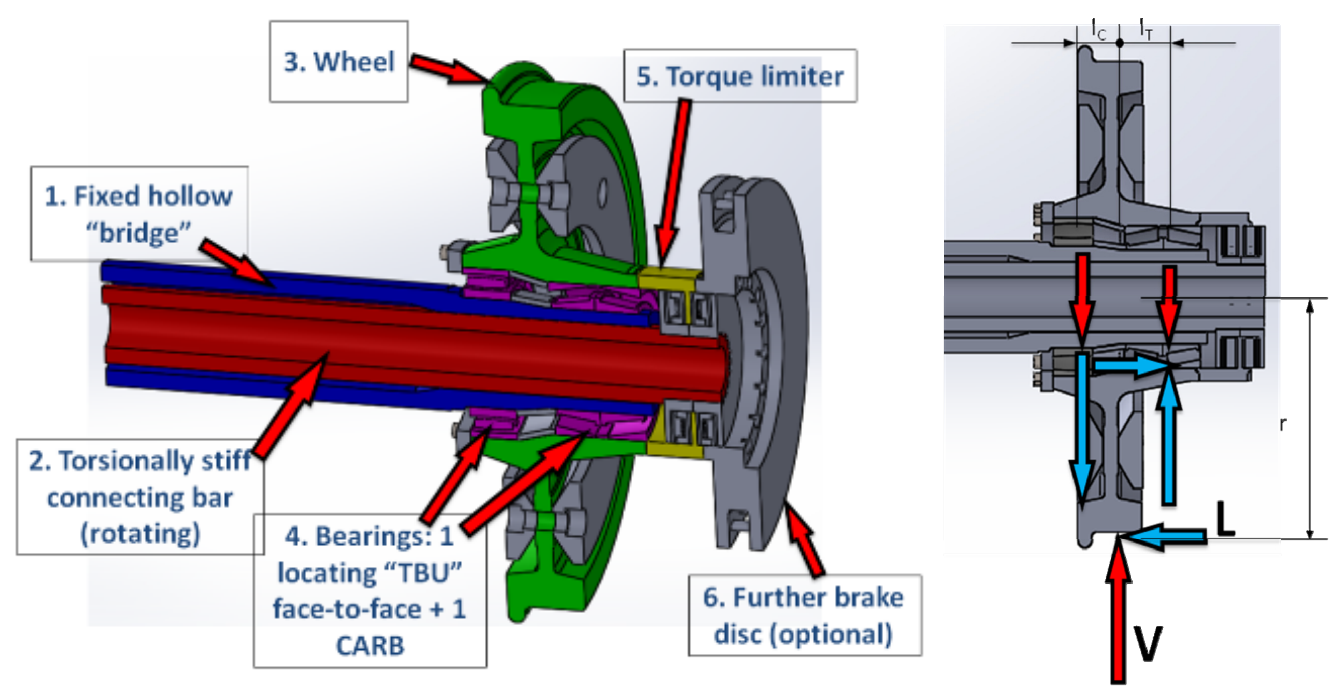

Figure 1: Left: the partially independently rotating wheelsets layout [12]. Right: Loads acting on the bearings of the AIR Wheelset due to wheel/rail typical vertical $V$ and lateral $L$ contact forces. Reactions are shown for a toroidal (non-locating) and a modified TBU (locating) rolling bearings. 
Figure 1 describes the combined effect of a lateral load $L$ and a vertical load $V$ on the bearings equipping the AIR Wheelset. While the vertical load $V$ is shared between the bearings depending on the $l_{C} l_{T}$ ratio, the lateral load $L$ generates a torque $L r$ that depends on the wheel radius $r$ that is supported by a pair of forces such that $\Delta F_{r} *\left(l_{C}+l_{T}\right)=L r$.

The direction (inwards or outwards) of the lateral force $L$ and its magnitude may sensibly affect the life of the bearings. In the proposed design, the inner bearing is of radial type (non-locating), supporting therefore larger loads when the force direction is the one indicated in Figure 1; on the opposite, the same loads reduce the radial load on the outer bearing (locating), that is nevertheless stressed also by the axial load.

It is evident that the practical choice of the bearings is affected by a number of parameters, including mass, space, desired rating life, type of bearings, etc. The design proposed here is just one of the many possible with existing rolling bearings, and it important to underline that specific solutions can only be designed according to specific needs, such as speed, axleload, operating scenarios, etc.

In the following, the practical application of real forces on two different designs of the AIR wheelset are shown. Both the design include the following bearings:

- a radial toroidal rolling bearing (such as the CARB ${ }^{\circledR}$ from SKF or the TORB ${ }^{\circledR}$ from FAG Schaeffler) is used as the non-locating internal bearing. This choice comes from the high rating life, high speed rating, low radial thickness and axial and angular self-aligning properties;

- a modified TBU (Tapered Bearing Unit) is used as the locating external bearing, supporting both radial and axial loads (when present). As by itself a pair of matched back-to-back tapered rolling bearings can withstand torques resulting in a possibly overconstrained solution, the AIR wheelset uses a faceto-face bearings matching. This arrangement requires an easily achievable design and is completely neutral from the life calculation point of view, being exactly the same as the one for a conventional TBU. In any case, an equivalent arrangement can be obtained by pairing two standard TRB (Tapered rolling bearings); it should be noted in this case that standard TRBs have a greater cone angle compared to railway TBUs as they are designed to withstand higher lateral loads. Also this solution will be used and described later.

It is evident that the "standard" calculations described in the above paragraphs are useless as they make use of empirical parameters that are valid only for the "standard" architecture of a wheelset and of its bearings. The life estimation can therefore be performed only by using damage accumulation rules based on actual loads.

\section{Available and "equivalent" wheel/rail contact forces}

\subsection{Experimental data treatment}

In order to obtain a reasonable life estimation it was mandatory to apply real loads on the bearings. This is a critical task as the wheel/rail forces during service are 
substantially unknown and may vary for the same vehicle depending on the operating scenario. It is not infrequent, in fact, that the same vehicle (e.g. a passenger car) is used in completely different situations, ranging from mainly flat areas at relatively high speed $(160 \div 200 \mathrm{~km} / \mathrm{h})$ to hilly or mountainous areas at much lower speed $(80 \div 120 \mathrm{~km} / \mathrm{h})$. As it will be shown, the influence of lateral forces is crucial as well as the vehicle loading conditions. For this latter parameter, commuter trains run a non negligible part of their life at nearly the maximum payload, while long-distance coaches often run near the running order mass. The uncertainty in this kind of calculations is therefore intrinsically very high.

Lateral and vertical forces can be measured in a variety of ways both on-board and trackside [14], but for the current work the only possibility is the use of instrumented wheelsets, i.e. properly calibrated wheelsets (see for example [15]) that continuously measure both the lateral and the vertical forces at both the wheel/rail contacts.

These "instruments" are central in the testing for the acceptance of characteristics of railway vehicles in terms of running safety ([5], [16]). According to these standards, vertical $Q$ and lateral $Y$ forces for right and left wheels of wheelsets 1 and 4 of a two bogies vehicle are indicated respectively with $Q_{11}, Q_{12}, Y_{11}, Y_{12}$ and $Q_{41}$, $Q_{42}, Y_{41}, Y_{42}$.

To get a sufficiently reliable amount of data for this goal, the line where the tests are conducted is categorized in four "test zones", from very sharp curves $(\mathrm{R}=250 \mathrm{~m})$ to straight track. The standard requires a number of "valid sections" of prescribed length as well as a certain distribution of track geometry defects to assess the running behaviour in all possible operating conditions. Tests are conducted in both empty ("operational mass in working order") and loaded ("design mass under normal payload") conditions and, if needed, with degraded suspension elements scenarios (deflated airsprings, malfunctioning yaw dampers, etc.).

Experimental data coming from a type test campaign of a new vehicle (a double deck passenger car for regional service) were available for this paper, as follows:

- straight track and very large-radius curves (zone 1) for loaded and empty vehicle for wheelset 4 (last wheelset, i.e. $Q_{41}, Q_{42}, Y_{41}, Y_{42}$ );

- large-radius curves (zone 2) for loaded and empty vehicle for wheelset 1 (first wheelset, i.e. $\left.Q_{11}, Q_{12}, Y_{11}, Y_{12}\right)$;

- small and very-small radius curves (zones $3+4$ ) for loaded and empty vehicle for wheelset 1 (first wheelset, i.e. $Q_{11}, Q_{12}, Y_{11}, Y_{12}$ ).

Although this data set seems incomplete, it makes sense as in zone 1 trackshifting forces are higher on wheelset 4 (low cant deficiency) while flange forces are predominant in zones 2, 3 and 4 on wheelset 1 (high cant deficiency).

Available data were sampled at a constant frequency of $500 \mathrm{~Hz}$ and low-pass filtered at $100 \mathrm{~Hz}$. As running safety standards require the evaluation of running safety related values averaging the data with a moving average taken every $0.5 \mathrm{~m}$ on $2 \mathrm{~m}$ window, raw data were treated in order to get such values as follows:

- the current position is estimated simply by integrating the speed; 
- time limits on the time history for the $2 \mathrm{~m}$ window are therefore calculated on the basis of the current position and speed;

- lateral and vertical forces acting on each wheel are calculated as the average of the signal included in the window on the basis of the "equivalent damage" (see below);

- the window is shifted by the time equivalent to $0.5 \mathrm{~m}$ restarting the process.

The "equivalent damage" force at the current position $s$ is calculated taking into account that the forces average according to eqn. (1), i.e. non linearly for vertical and lateral forces. For a continuous process this would lead to

$$
\left[Q_{e q}\right]_{2 m}=\left[\frac{1}{n} \int_{s}^{s+2 m} Q_{i}^{10 / 3} d x\right]^{3 / 10} ; \quad\left[Y_{e q}\right]_{2 m}=\left[\frac{1}{n} \int_{s}^{s+2 m} Y_{i}^{10 / 3} d x\right]^{3 / 10}
$$

while obviously for a discretised process the integrals turn to summations, resulting in "equivalent damage contact forces" that are wrong for running dynamics calculations but that are correct to estimate bearings life according to conventional ISO formula only.

\subsection{A simulated mixed scenario}

Running in tangent track for the AIR wheelset would result in an extraordinary long life, as the load rating of the bearings is more than doubled. On the opposite, running continuously in sharp curves or with high cant deficiency could be detrimental as the lateral wheel-rail force at each contact is entirely supported by the respective tapered bearings pair.

The choice of the data becomes therefore critical. Nevertheless, whatever the split of the operation simulated, a comparison between the conventional and the AIR solution can be performed. Of all the possible combinations, it was decided at the end to use a "mixed" scenario where the damage from all possible conditions is superimposed.

Figure 2 shows the "equivalent" vertical and lateral forces calculated for a wheelset along the entire measured distance $(449 \mathrm{~km})$ as follows:

- zone 2: one section loaded (Z2L, front) + one section empty (Z2E, front), for a total of $156 \mathrm{~km}(34.7 \%)$;

- zones 3+4: two sections loaded $(\mathrm{Z} 3+4 \mathrm{~L}$, front $)+$ one section empty $(\mathrm{Z} 3+4 \mathrm{E}$, front), for a total of $69 \mathrm{~km}(15.4 \%)$;

- zone 1: two sections loaded (Z1L, rear) + two sections empty (Z1E, rear), for a total of $224 \mathrm{~km}(49.9 \%)$. 

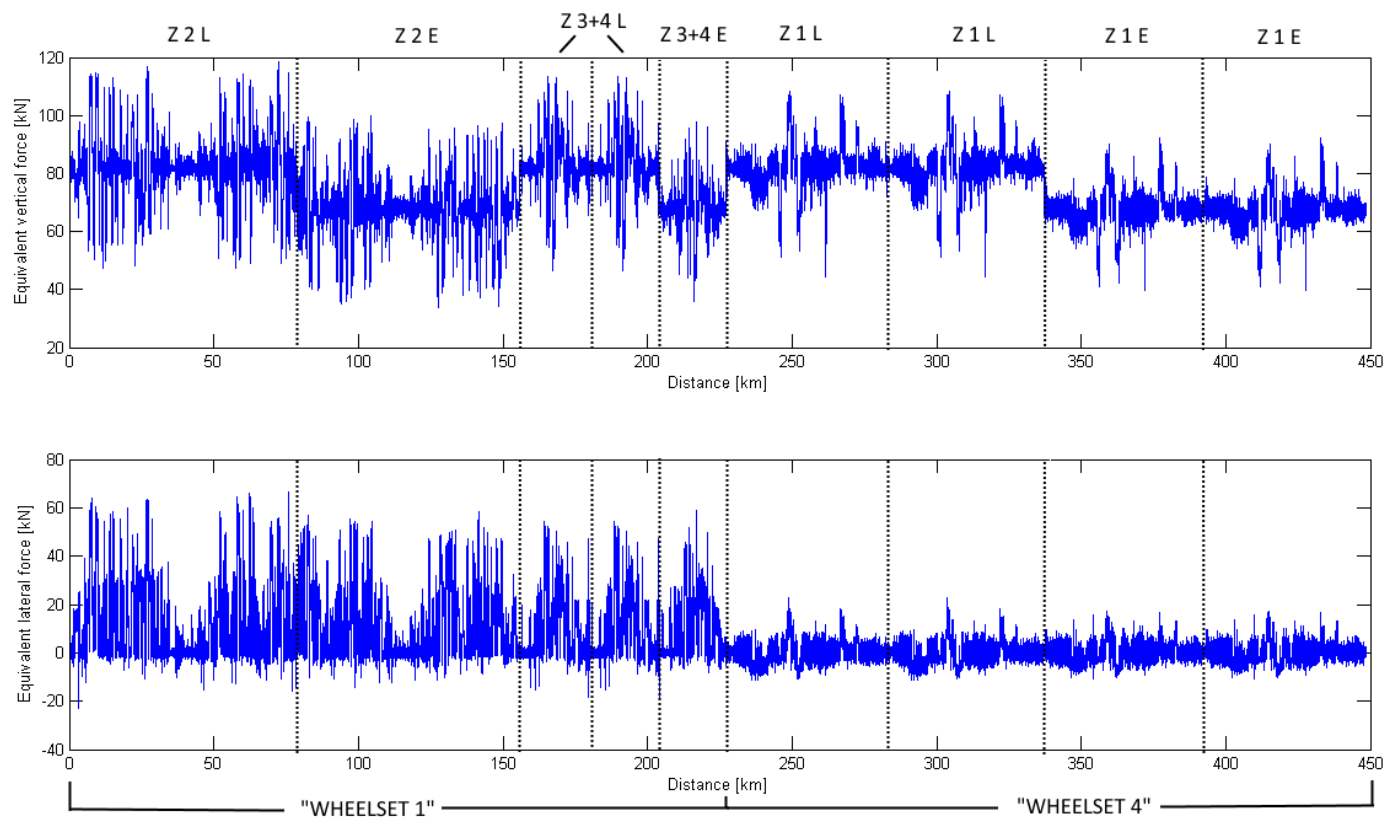

Figure 2: "Equivalent forces" for a wheelset of the available vehicle data set.

This hypothetic runs result in an equal distance covered by the instrumented wheel as the front (wheelset 1) and the last (wheelset 4) of the vehicle.

\section{Rolling bearings life estimation}

\subsection{Damage accumulation in rolling bearings}

The evaluation of the bearings life was done as follows on the basis of the treated experimental data shown above:

- from the wheel/rail "equivalent wheel/rail contact forces" on both wheels defined above and the geometry of the bearings arrangement, the radial $F_{r}$ and axial $F_{a}$ loads on all the bearings equipping a wheelset were found;

- by using the coefficients $e, Y_{1}$ and $Y_{2}$ for each bearing the equivalent bearing load $P$ was calculated according to (2), resulting in a set of diagrams such as the one shown e.g. in Figure 3;

- considering that the equivalent bearing load continuously varies along the run, the histogram of the occurrences of $P$ is calculated (Figure 4);

- calculation of the life cycle fractions $U_{i}=N_{i} / N$ under the equivalent loads $P_{i}$ acting on duty intervals is done on the basis of Figure 5; 


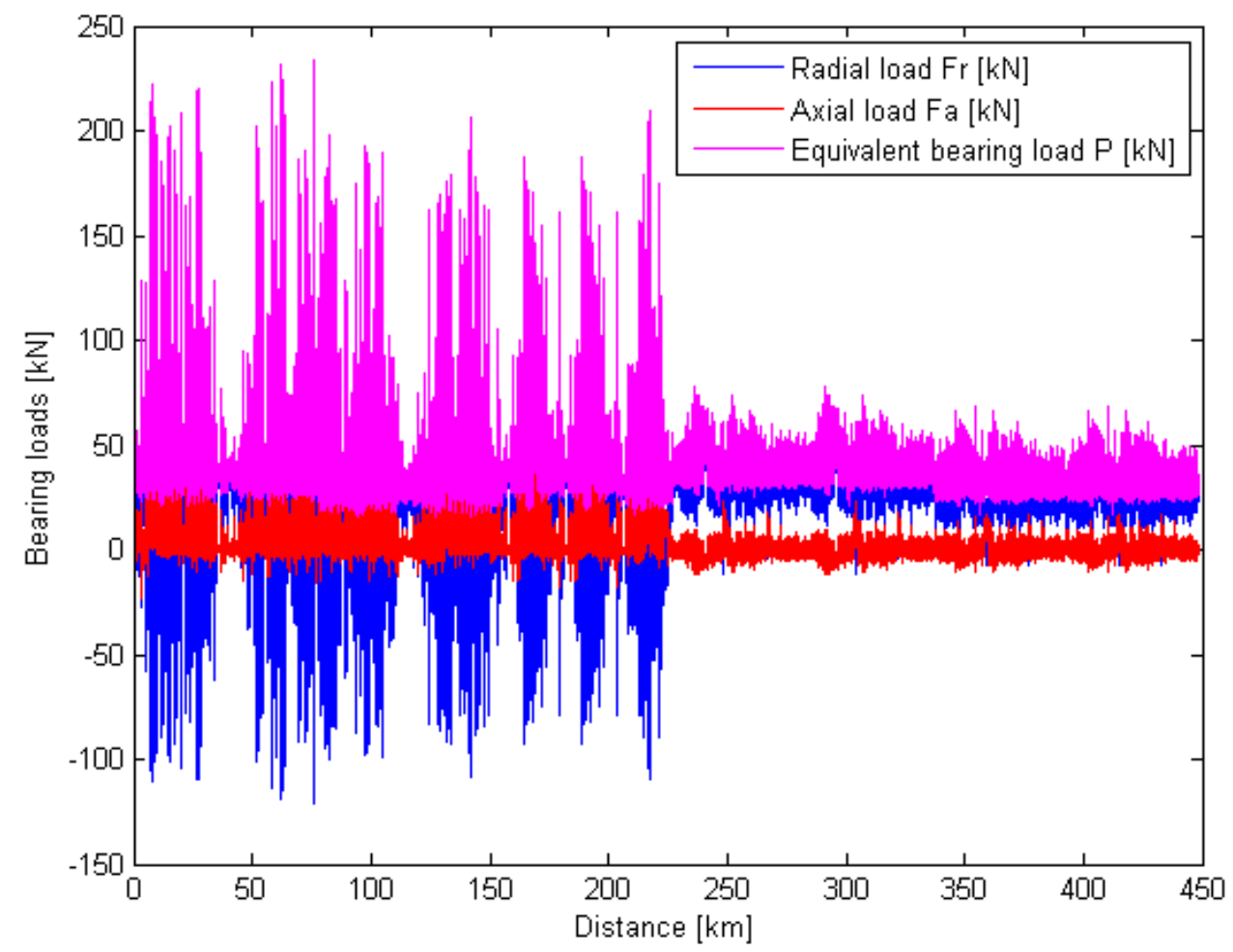

Figure 3: Equivalent load on a bearing deriving from the equivalent damage wheel/rail contact forces, the radial $F_{r}$ and axial $F_{a}$ loads and the bearing coefficients $Y_{1}$ and $Y_{2}$.

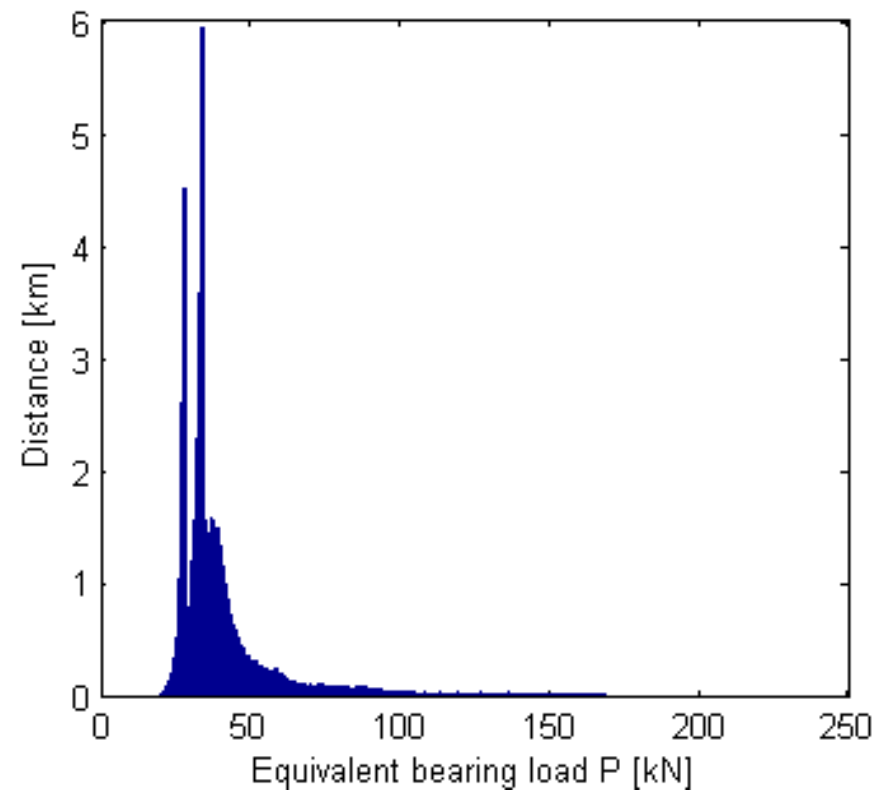

Figure 4: Histogram of distribution of the equivalent load $P$ on the tapered rolling bearing for one of the analysed configurations. The peaks are corresponding to the equivalent bearing load on straight track with empty and loaded vehicle. 

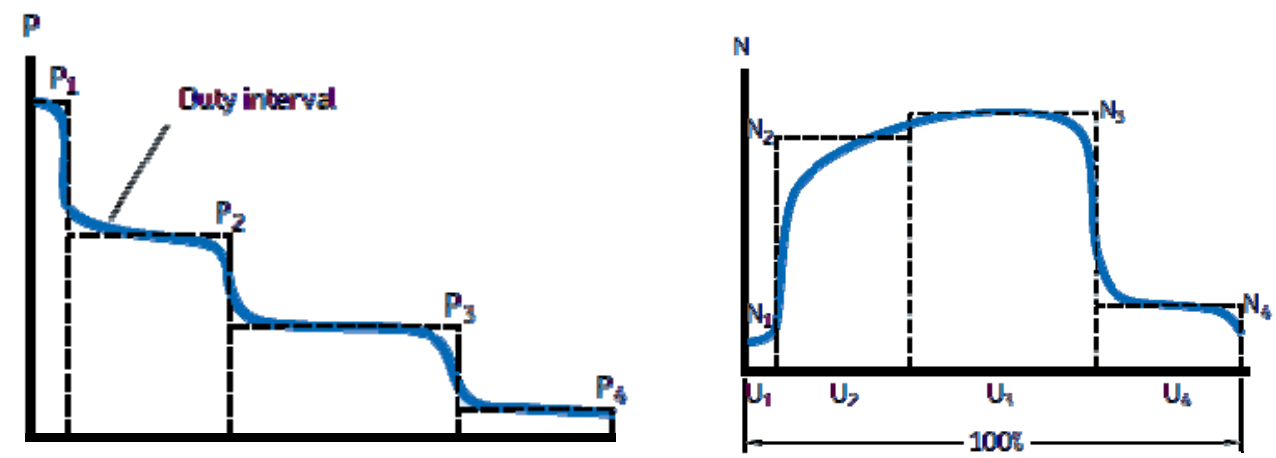

Figure 5: Definition of "Duty interval" $P_{i}$ and the corresponding number of revolutions $N_{i}$ resulting in life cycle fractions $U_{i}$.

- calculation of the basic rating life according to the following equation [17], considering that $\Sigma U_{i}=100 \%$

$$
L_{10 m}=\frac{1}{\frac{U_{1}}{L_{10 m 1}}+\frac{U_{2}}{L_{10 m 2}}+\frac{U_{3}}{L_{10 m 3}}+\ldots}
$$

\subsection{Results for a double-deck passenger car}

The development of the AIR Wheelset, based on the running dynamics simulation of the ERRI Wagon [9], led to a connecting shaft with a diameter of $140 \mathrm{~mm}$. At that time the data of the wheel/rail forces were not available and the estimation of bearings life was done by empirically doubling the constant lateral force acting during the tests described by the EN 12082 [2]. As long as a multibody dynamics model of the double-deck passenger car was not available, it was assumed that the aforementioned size of the shaft guarantees the stability of the vehicle.

By using the data available, three solutions were validated compared to the "reference" design of the wheelset, that incorporates a FAG Schaeffler TAROL 130 bearing unit. Figure 6 shows the geometry of the proposed solutions, that consider the constraints on maximum wheel bore length and diameter as well as the size of adjacent and mating parts.

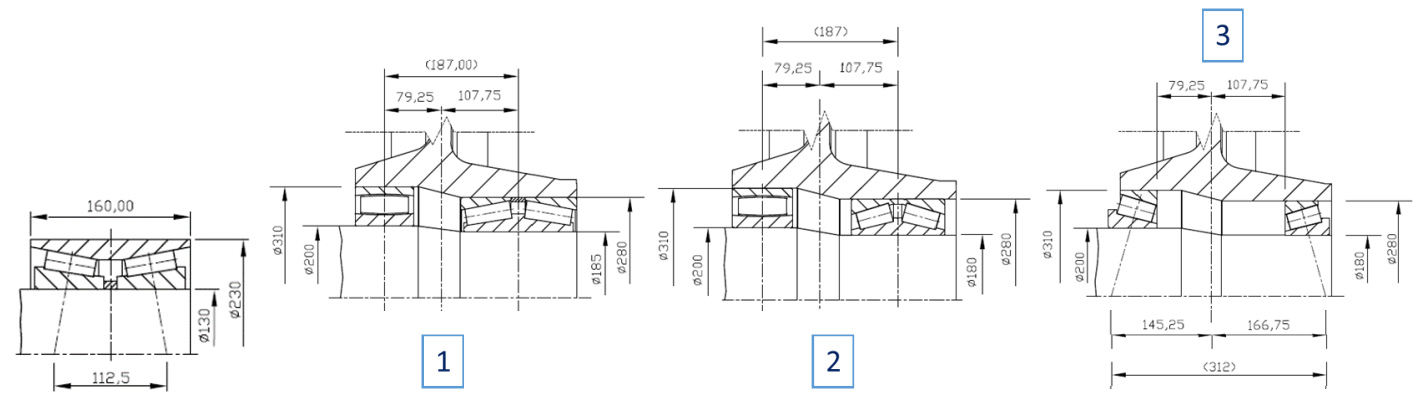

Figure 6: Left: reference bearing unit (TAROL 130). Right: three possible bearing arrangements for the AIR Wheelset. 
The estimated rating life for these solutions is shown in Table 1. The following conclusions can be drawn:

- all solutions have a rating life equal to or greater than the conventional wheelset bearings;

- the solution with two tapered rolling bearings $32040 \mathrm{X}+32036 \mathrm{X}$ appears to be on the average the less robust one and may have other problems related to the long distance of the bearings and the play adjustment that is needed for this arrangement but that is critical as well;

- the solution that incorporates the modified TBU (face-to-face version) has the lowest rating life. This can be explained by the small cone angle $\left(10^{\circ}\right)$ that makes this bearing more sensitive to axial load;

- the very similar arrangement with two tapered rolling bearings matched face-toface $32036 \mathrm{X} / \mathrm{DF}$ has an overall life in the excess of about 20 million km, indicating that this solution can be downsized without major problems;

- downsizing this solution is nevertheless quite difficult, as bearings cannot be found in any arbitrary size and the diameter of the connecting shaft and of the resulting stub axle drive the overall design of the solution.

\begin{tabular}{|c|c|c|c|c|c|}
\hline Solution & $\begin{array}{c}\text { Bearing } \\
\text { designation }\end{array}$ & $\begin{array}{c}\text { Dynamic load } \\
\text { rating } \boldsymbol{C}[\mathbf{k N}]\end{array}$ & $\begin{array}{c}\text { Reference } \\
\text { speed } \\
{[\mathbf{r} / \mathbf{m i n}]}\end{array}$ & $\begin{array}{c}\text { Cone angle } \\
{[\mathbf{d e g}]}\end{array}$ & $\begin{array}{c}\text { Rating life } \\
{[\text { million km] }}\end{array}$ \\
\hline 0 & TAROL 130 & 850 & - & 10 & 6 \\
\hline \multirow{2}{*}{1} & $\mathrm{C} 3040$ & 1120 & 1700 & 0 & 19.5 \\
\cline { 2 - 6 } & $\begin{array}{c}\text { modified } \\
\text { TBU }\end{array}$ & 951.5 & 1617 & 10 & 5.9 \\
\hline \multirow{2}{*}{2} & $\mathrm{C} 3040$ & 1120 & 1700 & 0 & 19.4 \\
\cline { 2 - 6 } & $32036 \mathrm{X} / \mathrm{DF}$ & 1100 & 1300 & 16 & 30.6 \\
\hline \multirow{2}{*}{3} & $32040 \mathrm{X}$ & 748 & 1400 & 16 & 13.3 \\
\cline { 2 - 6 } & $32036 \mathrm{X}$ & 644 & 1600 & 16 & 7.2 \\
\hline
\end{tabular}

Table 1: Estimated rating life in million $\mathrm{km}$ for the reference and the proposed solutions

\subsection{Results for a single-deck EMU}

Quite recently, the authors had access to the multibody model of a single deck EMU, with a similar axleload to the previous vehicle. This allowed to perform running dynamics simulations on a vehicle different from the ERRI Wagon, reaching the conclusion that a less stiff connecting shaft was sufficient. The minimum stiffness required resulted to be around $0.65 \mathrm{MNm} / \mathrm{rad}$, i.e. a hollow shaft with external and internal diameters respectively of $120 \mathrm{~mm}$ and $80 \mathrm{~mm}$. This allowed a complete redesign of the solution, incorporating lighter components and smaller bearings.

The running dynamics tests for this vehicle are ongoing at the time of writing. They are scheduled to be completed on three consecutive weeks starting on 25 January 2016 for zone 1, while results for zone 2 and zones $3+4$ are already available. The authors hope to be able to present the results of the full validation of 
the new solution at the time of the conference. Nevertheless the calculations were repeated by keeping the data for the double-deck car as:

- the axleload is similar, and as the single-deck EMU has a lower centre of gravity leading to a lower loading of the outer wheel for the same cant deficiency conditions;

- maximum speed is exactly the same $(160 \mathrm{~km} / \mathrm{h})$ as well as the type of service;

- a preliminary analysis of zone 2 and zones $3+4$ data confirms the assumption that loads are consistently similar.

The developed solution descends from solution 2 for the double-deck, i.e. includes a smaller CARB bearing (C4032) and a pair of face-to-faced matched tapered rolling bearings $(32032 \mathrm{X} / \mathrm{DF})$. The standard bearing unit used on the vehicle is the SKF TBU $150(\mathrm{C}=968 \mathrm{kN})$, that appears slightly oversized for the application resulting in a rating life of approximately 8.6 million $\mathrm{km}$ under the adopted loading scenario.

When applying the wheel/rail contact forces to the original wheel hub it was soon realized that the estimated rating life is too long, mainly because of the large distance between the bearings (Figure 7, (a) left). This allowed to shorten the stub axle; considering that both the stub axle and the wheel hub are cylindrical with constant diameter (i.e. easier machining and checking) the new solution appears to be particularly attractive (Figure 7, (b) left).

An optimization was conducted by reducing step by step the length of the stub axle until the same life of 6 million $\mathrm{km}$ was achieved on both the bearings used in the arrangement, changing correspondingly the $l_{C} / l_{T}$ ratio to get the best compromise. Figure 7 (b) right shows that the CARB bearing, having been downsized more than the tapered bearings, needs to be less loaded. This makes the wheel thinner at the hub and more protruded inside the wheel nominal circle. The optimal solution is found for $l_{t o t}=144 \mathrm{~mm}$ and $l_{T} / l_{t o t}=0.29$.
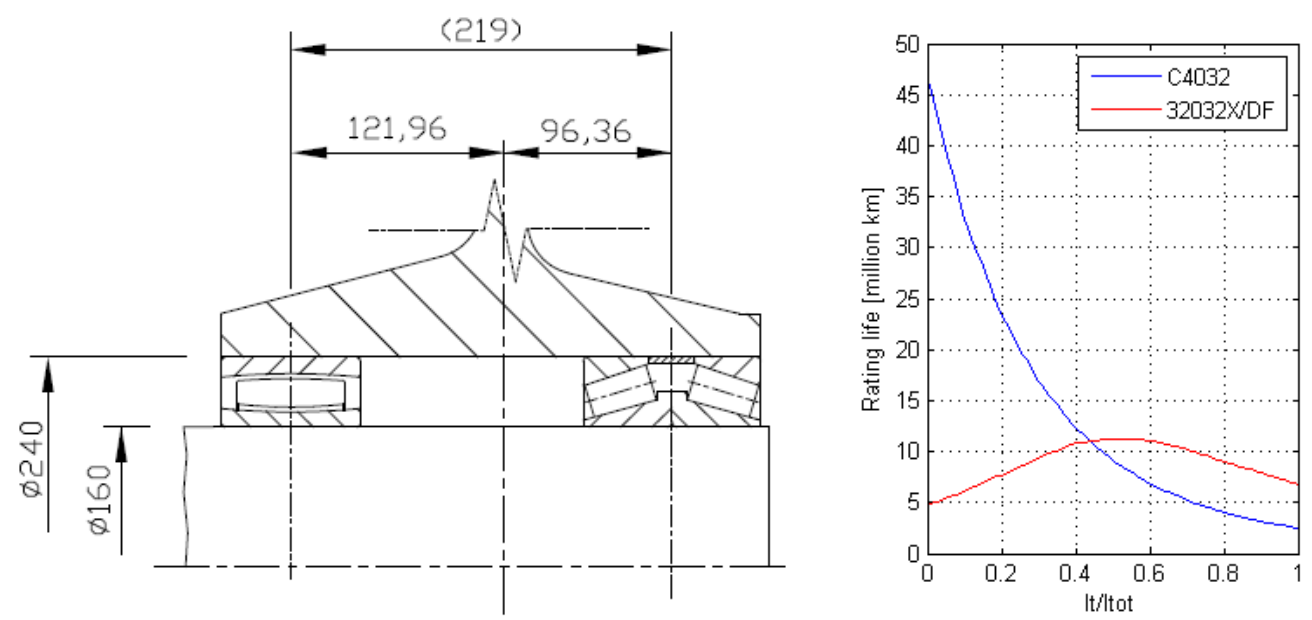

Figure 7 (a): Sketch (left) and estimated life (right) of the solution adopted for the single-deck EMU: original length of the wheel hub of $310 \mathrm{~mm}$. 

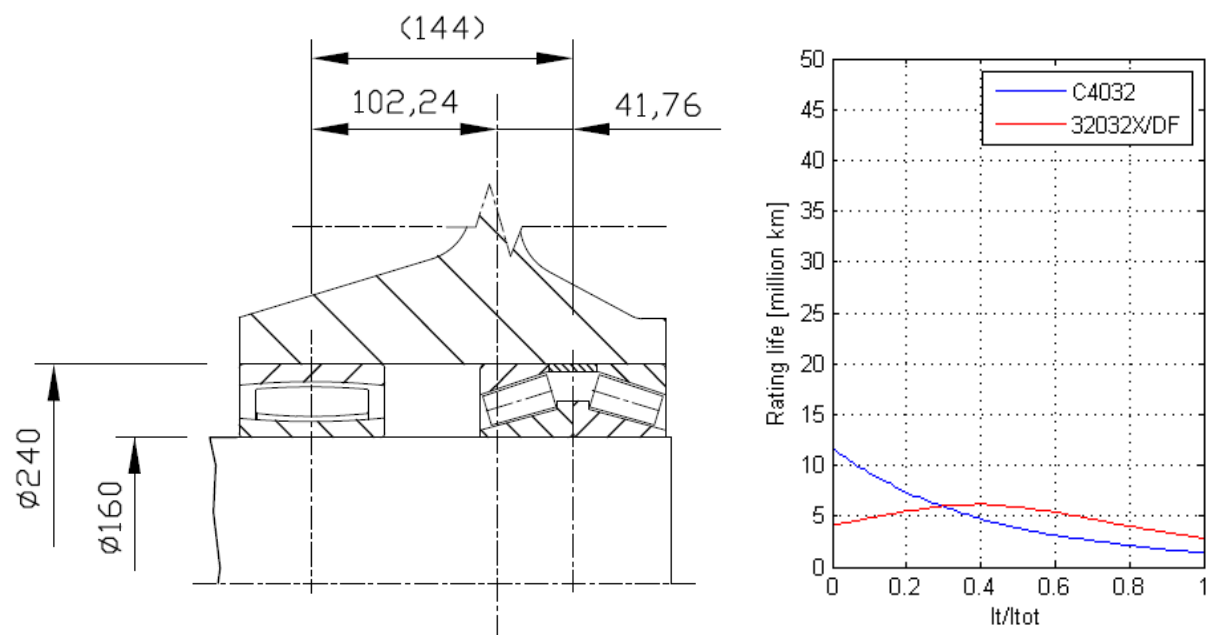

Figure 7 (b): Sketch (left) and estimated life (right) of the solution adopted for the single-deck EMU: final solution with length $235 \mathrm{~mm}$.

\section{Conclusions}

The paper has shown how the conventional approach to bearing calculations for axleboxes cannot be applied to an innovative wheelset whose wheels are "apparently" independently rotating and incorporate the relative bearings.

Rating life estimation and design validation were conducted therefore by using a service scenario based on vertical and lateral forces collected at the wheel/rail interface during type tests needed for the running safety homologation of new vehicles. This allowed to apply the basic relationships of bearing life and to compare the life of the conventional tapered rolling bearings to several solutions proposed for the AIR wheelset.

Results are very promising. The different solutions individually appear to have rating lives in line with conventional bearings, allowing further development that will include tests on roller rigs and, in the future, on vehicles. It is important to highlight that the solutions proposed here should be considered "unconventional" only on railways, while those bearing arrangements are absolutely common in all other industry fields.

\section{References}

[1] ISO 281:2007, "Rolling bearings - Dynamic load ratings and rating life"

[2] EN 12082:2010, "Railway applications - Axleboxes - Performance testing"

[3] UIC Code 515-5, "Matériel roulant moteur et remorqué - Bogies organes de roulement - Essais des boites d'essieux", Paris, 1994

[4] Prud'homme, A., "La résistance de la voie aux efforts transversaux exercés par le matériel roulant", Revue Générale des Chemins de Fer, Janvier 1967. 
[5] FprEN 14363 :2015, "Railway applications - Testing and Simulation for the acceptance of running characteristics of railway vehicles - Running Behaviour and stationary tests" CEN, Brussels, 2015.

[6] SKF, "Railway Technical Handbook, Volume 1, Axleboxes, wheelset bearings, sensors, condition monitoring, subsystem and services", July 2011, ISBN 978-91-978966-3-4.

[7] AB Consulting sas di Andrea Bracciali \& C., "Railway Wheelset With Partially Independent Wheels", International patent PCT/IB2015/051855 (13.03.2015), European patent EP15173213.8 (22.06.2015).

[8] A. Bracciali, "Apparently Independently Rotating Wheelset - a possible solution for all needs?", The Stephenson Conference - Research For Railways, Institution of Mechanical Engineers, London, UK, 21-23 April 2015.

[9] A. Bracciali, G. Megna, "Running dynamics of railway vehicles equipped with torsionally flexible axles and partially independently rotating wheels", 24th IAVSD, Graz, Austria, 17-21 August 2015.

[10] A. Bracciali, G. Megna: "Contact Mechanics Issues Of A Vehicle Equipped With Partially Independently Rotating Wheelsets", Contact Mechanics 2015 Conference, 30.8-3.9.2015, Colorado Springs, USA.

[11] A. Bracciali, G. Megna, "Validation of the design of the torque limiter of the AIR Wheelset on the Sardinian backbone network", to be presented at the Third International Conference on Railway Technology, 5-8 April 2015, Cagliari, Italy.

[12] A. Bracciali, "Railway wheelsets: history, research and developments", to be presented at the Third International Conference on Railway Technology, 5-8 April 2015, Cagliari, Italy.

[13] A. Bracciali, P. Cavicchi, A. Corbizi Fattori, "Maintainability of wheelsets: a novel solution to save time and money", submitted to 11th World Congress on Railway Research 2016, Milan, Italy, 29.5-2.6.2016.

[14] L. Bocciolini, A. Bracciali, L. Di Benedetto, R. Mastandrea, F. Piccioli, "Wayside Measurement of Lateral and Vertical Wheel/Rail Forces for Rolling Stock Homologation", in J. Pombo, (Editor), "Proceedings of the Second International Conference on Railway Technology: Research, Development and Maintenance", Civil-Comp Press, Stirlingshire, UK, Paper 171, 2014. doi:10.4203/ccp.104.171

[15] A. Bracciali, M. Macherelli, L. Bocciolini, "Design of an innovative test bench to calibrate instrumented wheelsets", to be presented at the Third International Conference on Railway Technology, 5-8 April 2015, Cagliari, Italy.

[16] UIC Code 518 (4 ${ }^{\text {th }}$ ed.), "Railway applications - Testing and Simulation for the acceptance of running characteristics of railway vehicles - Running Behaviour and stationary tests", Unione Internationale des Chemins de Fer, Paris, 2009

[17] SKF, "Rolling bearings", August 2013, PUB BU/P1 10000/2 EN. 